\title{
Rural-Urban Residence and Stroke Risk and Severity in Postmenopausal Women: The Women's Health Initiative
}

\author{
Shawnita Sealy-Jefferson, ${ }^{1, *}$ Molly Roseland, ${ }^{2}$ Michele L. Cote, ${ }^{3}$ Amy Lehman, ${ }^{4}$ Eric A. Whitsel, ${ }^{5}$ \\ Jason Booza, ${ }^{6}$ and Michael S. Simon ${ }^{3}$
}

\begin{abstract}
Background: The impact of rural-urban residence on stroke risk and poor stroke outcomes among postmenopausal women is unknown.

Methods: We used data from the Women's Health Initiative (WHI) $(1993-2014 ; n=155,186)$ to test the hypothesis that women who live in rural compared with urban areas have higher stroke risk and worse stroke outcomes than urban women. We used rural-urban commuting area codes to categorize geocoded participant addresses into urban, large rural, or small rural areas. Incident strokes during follow-up were adjudicated by neurologists who used standardized criteria for reviewing brain imaging reports and other medical records and determining stroke subtype. Stroke functional recovery was measured with the Glasgow Stroke Outcomes Scale ascertained from the hospital record. We used univariable and multivariable-adjusted Cox proportional hazards models as well as logistic regression models to test whether rural-urban residence predicted stroke risk and odds of poor stroke outcome. Results: Among the 155,186 women in our cohort, 2.3\% ( $n=3514)$ had an incident stroke. We observed a modest reduction in risk of incident stroke among women who lived in urban (adjusted hazard ratio [aHR]: 0.86, confidence interval [95\% Cl]: 0.71-1.05) and large rural areas (aHR: 0.79, 95\% Cl: 0.60-1.04) compared with women who lived in small rural areas. In contrast, women who lived in urban compared with large rural areas had a similarly modest increased risk of stroke (aHR: 1.09, 95\% Cl: 0.89-1.32). Women who lived in urban compared with large rural areas were more likely to have poor stroke outcome (odds ratio [OR]: 1.41, 95\% Cl: 1.06-1.88), but the association was attenuated after adjustment for covariates (adjusted OR [aOR]: 1.27, 0.93-1.74).
\end{abstract}

Conclusions: Future studies should confirm and examine the potential pathways of the reported associations among postmenopausal women.

Keywords: postmenopausal; rural-urban; stroke risk; stroke severity

\section{Introduction}

Stroke is the foremost cause of long-term adult morbidity and the fifth leading cause of death in the United States. Nearly 800,000 strokes occur each year ${ }^{1,2}$ costing an estimated $\$ 34$ billion/year in health care, medi- cation, and missed days of work. ${ }^{3,4}$ Stroke primarily affects older populations, with a doubling of risk for each additional decade of life after 55 years of age. ${ }^{5}$ It has been projected that the number of people who experience a stroke will increase by 3.4 million people by

\footnotetext{
${ }^{1}$ Division of Epidemiology, College of Public Health, The Ohio State University, Columbus, Ohio, USA.

${ }^{2}$ Beaumont Hospital, Oakwood Campus, Dearborn, Michigan, USA.

${ }^{3}$ Department of Oncology, Karmanos Cancer Institute Population Studies and Disparities Research Program, Wayne State University School of Medicine, Detroit, Michigan, USA.

${ }^{4}$ Center for Biostatistics, Ohio State University, Columbus, Ohio, USA.

${ }^{5}$ Department of Epidemiology, University of North Carolina at Chapel Hill, Chapel Hill, North Carolina, USA.

${ }^{6}$ Department of Family Medicine and Public Health Sciences, Wayne State University, Detroit, Michigan, USA.
}

*Address correspondence to: Shawnita Sealy-Jefferson, PhD, MPH, Division of Epidemiology, College of Public Health, The Ohio State University, 344 Cunz Hall, 1841 Neil Avenue, Columbus, OH 43210, USA, E-mail: sealy-jefferson.1@osu.edu

( ) Shawnita Sealy-Jefferson et al. 2020; Published by Mary Ann Liebert, Inc. This Open Access article is distributed under the terms of the Creative Commons License (http://creativecommons.org/licenses/by/4.0), which permits unrestricted use, distribution, and reproduction in any medium, provided the original work is properly cited. 
the year 2030, which represents a significant burden of stroke among U.S. residents. ${ }^{4}$

The menopausal transition has been identified as a period when many women develop risk factors for cardiovascular disease, including stroke. ${ }^{6}$ Women have a higher burden of stroke, likely because stroke risk increases with age, and women have a longer life expectancy than men. The majority of strokes occur in women aged $>70$ years, who are more likely to live alone, have constrained finances, are socially secluded, and have more comorbid diseases. ${ }^{4}$ After stroke, women are also half as likely as men to have independence in terms of activities of daily living. ${ }^{7}$

One fifth of the U.S. population lives in isolated rural areas, ${ }^{8}$ which are often fraught with longer travel times to access health care. ${ }^{9}$ Stroke risk is greatest in the rural southeast and coastal areas of the United States, ${ }^{10}$ but there are limited data on geographic differences in stroke risk and outcomes among older women. Stroke mortality is $30 \%$ higher in rural compared with urban areas in the United States, and preliminary evidence suggests that this disparity is due to a higher incidence rather than a higher case fatality among stroke patients. ${ }^{11,12}$ If incidence is indeed the driver of the rural mortality penalty, primary prevention may be effective at reducing the burden of stroke mortality in rural areas. ${ }^{11}$

There are also rural-urban disparities in acute stroke care that can be attributed to structural related barriers (organizational features, provider, facility, and access to care) and patient-level factors (eligibility for treatment and disease severity). ${ }^{13}$ There are striking and growing disparities in treatment for acute stroke in rural versus urban areas. ${ }^{13}$ Although rural residents are more likely to have a usual source of health care ${ }^{14}$ ("a place to which they usually go when they are sick"15), they are still less likely to have a local hospital and physician, ${ }^{16}$ more likely to be uninsured, ${ }^{17}$ and tend to report fewer annual health care visits. ${ }^{18}$ Such disparities may have an impact on stroke incidence in rural and urban areas given that the availability of health care resources has a strong influence on risk factor prevalence, ${ }^{19}$ awareness, treatment, and control. ${ }^{20}$

Most of the research on geographic disparities in stroke has been focused on understanding the higher stroke burden in the southeastern region (or so-called "Stroke Belt") of the United States. ${ }^{21}$ Although evidence of increased stroke mortality in this area has existed for decades, ${ }^{19}$ recent results from an ecological study suggest racial and urban-rural disparities in mortality rates among those residing outside of the Stroke belt. ${ }^{22}$ Conversely, evidence of geographic differences in stroke incidence is lacking. Using the National Health and Nutrition Examination Survey, researchers reported higher stroke incidence rates in southeastern compared with northeastern states, but inconsistent patterns were found among other regions. ${ }^{23}$ Results from the Reasons for Geographic and Racial Differences in Stroke study found that stroke risk was $23 \%$ higher in large rural towns, and 30\% higher in small rural/isolated areas, compared with urban areas. ${ }^{11}$ Importantly, stroke patients from rural areas may have higher comorbidity and risk factor profiles, ${ }^{24}$ receive lower quality stroke care, ${ }^{25,26}$ and delayed consultation with stroke neurologists, all of which could result in poor poststroke outcomes.

To extend the literature on rural-urban residence on stroke risk and outcomes, we examined whether ruralurban residence was associated with stroke risk and poststroke outcomes among a large cohort of racially/ ethnically diverse postmenopausal women from the Women's Health Initiative (WHI). We hypothesized that residence in small rural areas, compared with large rural and urban areas would be a significant predictor of stroke risk and poor stroke outcomes.

\section{Materials and Methods}

\section{Study population}

Details of the WHI have been published. ${ }^{27-29}$ In brief, a total of 161,808 postmenopausal women, from 40 U.S clinical centers, across 24 states and the District of Columbia, were randomized to overlapping dietary modification, calcium/vitamin $\mathrm{D}$, and hormone therapy clinical trials $(n=68,132)$ or enrolled in an observational study $(n=93,676)$, between 1993 and 1998 . Women were eligible to participate if they were between 50 and 79 years of age, willing to give informed consent, and expected to survive and not relocate during the next 3 years.

\section{Rural-urban classification}

We used Rural-Urban Commuting Area (RUCA) codes that classify all U.S. Census tracts into one of 10 main categories, as well as 33 subcategories based on secondary commuting flows. ${ }^{30}$ U.S. Census tracts provide more granular information about neighborhoods than larger county definitions. ${ }^{11}$ Study participant addresses were geocoded as previously described, ${ }^{31-33}$ and assigned a tract-level, RUCA code based on a reference document from the United States Department of Agriculture. ${ }^{30}$ Our analytic sample included 155,186 women whose addresses were linkable 
to the RUCA coding scheme $\leq 2$ years after they were randomized in the clinical trials or enrolled in the observational study.

We grouped the RUCA codes into four categories: (1) urban or "metropolitan" (codes: 1.0, 1.1, 2.0, 2.1, 3.0, 4.1, 5.1, 7.1, 8.1, 9.1, and 10.1); (2) large rural city/ town or "micropolitan" (codes: 4.0, 4.2, 5.0, 5.2, 6.0, and 6.1) (3) small rural town (codes: 7.0, 7.2, 7.3, 7.4, 8.0, 8.2, 8.3, 8.4, 9.0, and 9.2), and (4) isolated small rural town (codes: 10.0, 10.2, 10.3, 10.4, 10.5, and 10.6). Given the small number of study participants in the isolated small rural town, we combined this category with small rural town category for the analysis. RUCA's small census tract scale is able to uniquely capture fine spatial variation in rurality, allowing RUCA to classify individuals by geographic region more precisely than other county-based classification schemes. ${ }^{34}$ In addition, the RUCA classification emphasizes commuting flows, which are important to consider in the context of stroke diagnosis and treatment, since "communities to which persons flow (for employment) may also be places where they receive health care. ${ }^{34}$

\section{Covariates}

Potential confounders (variables that were likely to be associated with both outcome and exposure but not on the causal pathway linking exposure to outcomes) were identified from the literature, ${ }^{11}$ and included the following variables ascertained from the baseline interview: age, race/ethnicity (black, white, or other), income $(<\$ 20 \mathrm{k}, \$ 20-34,999, \$ 35-74,999$, and $\$ 75 \mathrm{k}+)$, education (none/some high school, high school/general equivalency degree, or more than high school), smoking status (former, current, or never), physical activity (metabolic equivalents/week), living alone (yes/no), history of medications to treat hypertension (yes/no), and history of atrial fibrillation (ever/never).

\section{Stroke incidence and severity}

Follow-up for incident stroke was performed at 6month intervals for the clinical trials and every year for the observational study through 2010. Study participants in the clinical trials had at least yearly follow-up clinic visits, and observational study participants provided follow-up information by mail. Women with self-reported stroke history at baseline were excluded from these analyses. The majority of strokes occurring during follow-up were adjudicated by neurologists who used standardized criteria for reviewing brain imaging reports and other medical records and determining stroke subtype. However, for our analytic sample, all strokes were adjudicated. Strokes were classified as ischemic (thrombotic or embolic occlusion of a cerebral artery or lacunar infarction not related to a procedure), hemorrhagic (subarachnoid, intracerebral, or other undetermined intracranial hemorrhage not related to procedure), or unknown stroke type when a stroke was documented, but type could not be determined. ${ }^{35}$

Stroke functional recovery was measured with the Glasgow Stroke Outcomes Scale ascertained from the hospital record, and was categorized as (1) good recovery (able to resume work or school), (2) moderate disability (able to live independently, but not able to resume work or school), (3) severe disability (able to follow commands, unable to live independently), (4) vegetative survival, (5) death, and (6) unable to assess.

\section{Statistical analysis}

Our analytic sample included 155,187 women for whom we were able to assign a RUCA code to their address. One woman had a stroke on day 0 , so was not included in our Cox models, leaving 155,186 women in our analytic sample. We calculated frequencies of baseline sociodemographics, clinical factors, and stroke risk factors, overall and by incident stroke status. We also summarized the clinical characteristics of women diagnosed with a stroke, according to rural-urban classification. We used univariable and multivariable-adjusted Cox proportional hazards models to quantify the association between RUCA code and incident stroke.

For all models, participant age used as the time scale, and the baseline hazard was stratified by trial membership. The Glasgow outcome scale was dichotomized as good recovery $(1,2)$ versus poor recovery $(3,4,5)$. We used univariable and multivariable logistic regression models to quantify the association between urbanrural residence and stroke outcome, among women who had available data on stroke recovery. Analyses were performed using SAS/STAT software, Version 9.4 of the SAS System for Windows (SAS Institute, Inc., Cary, NC). Finally, we take heed to recent calls to retire statistical significance, in favor of more detailed and nuanced statistical analyses and interpretation of results, recognizing that $p$-values and decisions regarding which research ideas should be explored further have no association. ${ }^{36}$

\section{Results}

Of 155,186 study participants, $2.3 \%(n=3514)$ had an incident stroke (Table 1), during an average follow- 
Table 1. (Continued)

Table 1. Demographic Characteristics of Study Participant in Women's Health Initiative $(n=155,186)$ and Stratified by Incident Stroke Status, 1993-2010

\begin{tabular}{|c|c|c|c|c|c|c|c|}
\hline \multirow[b]{2}{*}{ Characteristic } & \multirow{2}{*}{$\begin{array}{c}\text { Total sample, } \\
N=155,186 \\
(\%)\end{array}$} & \multirow{2}{*}{$\begin{array}{c}\text { No stroke, } \\
N=151,672 \\
(\%)\end{array}$} & \multirow{2}{*}{$\begin{array}{c}\text { Stroke, } \\
N=3514 \\
(\%)\end{array}$} & Characteristic & $\begin{array}{c}N=155,186 \\
(\%)\end{array}$ & $\begin{array}{c}N=151,672 \\
(\%)\end{array}$ & $\begin{array}{c}N=3514 \\
(\%)\end{array}$ \\
\hline & & & & $\begin{array}{l}\text { Alcohol } \\
\text { Nondrinker }\end{array}$ & $45,722(29 \%)$ & $44,450(29 \%)$ & $1272(36 \%)$ \\
\hline Age & & & & Former drinker & $90,360(58 \%)$ & $88,543(58 \%)$ & $1817(52 \%)$ \\
\hline $50-59$ & $50,709(33 \%)$ & $50,300(33 \%)$ & $409(12 \%)$ & Current drinker & $18,003(12 \%)$ & $17,607(12 \%)$ & $396(11 \%)$ \\
\hline $60-69$ & $70,015(45 \%)$ & $68,533(45 \%)$ & $1482(42 \%)$ & Smoking & & & \\
\hline $70-79$ & $34,462(22 \%)$ & $32,839(22 \%)$ & $1623(46 \%)$ & Never smoker & $78,321(50 \%)$ & $76,579(50 \%)$ & $1742(50 \%)$ \\
\hline Race & & & & Past smoker & $64,270(41 \%)$ & $62,871(41 \%)$ & $1399(40 \%)$ \\
\hline Black & $13,204(9 \%)$ & $12,841(8 \%)$ & $363(10 \%)$ & Current smoker & $10,554(7 \%)$ & $10,229(7 \%)$ & $325(9 \%)$ \\
\hline White & $128,831(83 \%)$ & $125,907(83 \%)$ & $2924(83 \%)$ & Self-rated health & & & \\
\hline Other & $12,749(8 \%)$ & $12,538(8 \%)$ & $211(6 \%)$ & Excellent/very good & $89,456(58 \%)$ & $87,911(58 \%)$ & $1545(44 \%)$ \\
\hline Education & & & & Good & $50,771(33 \%)$ & $49,397(33 \%)$ & $1374(39 \%)$ \\
\hline None/some HS & 8185 (5\%) & 7923 (5\%) & $262(7 \%)$ & Fair/poor & $13,947(9 \%)$ & $13,382(9 \%)$ & $565(16 \%)$ \\
\hline HS/GED & $26,594(17 \%)$ & $25,926(17 \%)$ & $668(19 \%)$ & \multicolumn{4}{|c|}{ Physical activity (MET/week) } \\
\hline$>\mathrm{HS}$ & $58,286(38 \%)$ & $56,915(38 \%)$ & $1371(39 \%)$ & None & $23,381(15 \%)$ & $22,741(15 \%)$ & $640(18 \%)$ \\
\hline Any insurance & & & & $>0-3.75$ & $21,637(14 \%)$ & $21,087(14 \%)$ & $550(16 \%)$ \\
\hline No & $6815(4 \%)$ & $6712(4 \%)$ & $103(3 \%)$ & $3.75-8.75$ & $30,421(20 \%)$ & $29,728(20 \%)$ & $693(20 \%)$ \\
\hline Yes & $146,875(95 \%)$ & $143,500(95 \%)$ & $3375(96 \%)$ & $8.75-17.5$ & $33,480(22 \%)$ & $32,771(22 \%)$ & 709 (20\%) \\
\hline Income & & & & $\geq 17.5$ & $38,950(25 \%)$ & $38,211(25 \%)$ & 739 (21\%) \\
\hline$<\$ 20,000$ & $24,192(16 \%)$ & $23,316(15 \%)$ & $876(25 \%)$ & \multicolumn{4}{|l|}{ RUCA class } \\
\hline$\$ 20 k-\$ 34,999$ & $35,261(23 \%)$ & $34,305(23 \%)$ & $956(27 \%)$ & Urban & $144,937(93 \%)$ & $141,669(93 \%)$ & 3268 (93\%) \\
\hline$\$ 35 k-\$ 74,999$ & $58,465(38 \%)$ & $57,371(38 \%)$ & $1094(31 \%)$ & Large rural & $5928(4 \%)$ & $5799(4 \%)$ & $129(4 \%)$ \\
\hline$\$ 75 \mathrm{k}+$ & $26,863(17 \%)$ & $26,516(17 \%)$ & $347(10 \%)$ & Small rural & $2331(2 \%)$ & $2271(1 \%)$ & $60(2 \%)$ \\
\hline Hypertension & & & & Isolated small rural & $1990(1 \%)$ & 1933 (1\%) & $57(2 \%)$ \\
\hline Never & $96,873(62 \%)$ & $95,364(63 \%)$ & $1509(43 \%)$ & \multicolumn{4}{|c|}{ WHI Clinical Trial Membership } \\
\hline Untreated & $11,904(8 \%)$ & $11,554(8 \%)$ & $350(10 \%)$ & Observational study & $90,117(58)$ & $88,126(58)$ & $1991(57)$ \\
\hline Treated & $37,938(24 \%)$ & $36,520(24 \%)$ & $1418(40 \%)$ & E-alone trial & $6963(4)$ & $6734(4)$ & $229(7)$ \\
\hline High cholesterol pills & & & & $\mathrm{E}+\mathrm{P}$ trial & $11,471(7)$ & $11,177(7)$ & $294(8)$ \\
\hline No & $125,355(81 \%)$ & $122,689(81 \%)$ & $2666(76 \%)$ & DM trial & $38,966(25)$ & $38,176(25)$ & $790(22)$ \\
\hline Yes & $20,731(13 \%)$ & $20,111(13 \%)$ & $620(18 \%)$ & $\begin{array}{c}\text { E-alone/E+P } \\
\text { trial+DM }\end{array}$ & $7669(5)$ & 7459 (5) & $210(6)$ \\
\hline
\end{tabular}

DM, dietary modification; HS, high school; GED, general education diploma; RUCA, rural-urban commuting area; WHI, Women's Health Initiative.

Relative had a stroke 148,245 (96\%) $\quad 145,117(96 \%) \quad 3128(89 \%)$ $6804(4 \%) \quad 6424(4 \%) \quad 380(11 \%)$

No

$90,097(58 \%) \quad 88,305(58 \%) \quad 1792(51 \%)$ $56,205(36 \%) \quad 54,715(36 \%) \quad 1490(42 \%)$ Don't know $\quad 7822(5 \%) \quad 7619(5 \%) \quad 203(6 \%)$

No. of relatives who had a stroke

0

$90,097(58 \%) \quad 88,305(58 \%) \quad 1792(51 \%)$

$46,291(30 \%) \quad 45,150(30 \%) \quad 1141(32 \%)$

$8145(5 \%) \quad 7861(5 \%) \quad 284(8 \%)$

$\begin{array}{lccr}3 & 1129(1 \%) & 1082(1 \%) & 47(1 \%) \\ 4 \text { or more } & 427(<1 \%) & 415(<1 \%) & 12(<1 \%)\end{array}$

Atrial fibrillation

No

Yes

$145,757(94 \%) \quad 142,677(94 \%) \quad 3080(88 \%)$ $6820(4 \%) \quad 6472(4 \%) \quad 348(10 \%)$

Hormone therapy

Never used $E$ alone or $\mathrm{E}+\mathrm{P}$

Past user or $\mathrm{E}$ alone or $\mathrm{E}+\mathrm{P}$

Current user

of $E$

Current user

of $E+P$

$67,955(44 \%) \quad 66,274(44 \%) \quad 1681(48 \%)$

$24,888(16 \%) \quad 24,162(16 \%) \quad 726(21 \%)$

$35,110(23 \%) \quad 34,347(23 \%) \quad 763(22 \%)$

$27,104(17 \%) \quad 26,763(18 \%) \quad 341(10 \%)$

BMI (categorized)

$<25$

$25-29$

$30+$

$54,214(35 \%)$

$53,102(35 \%) \quad 1112(32 \%)$

$53,558(35 \%) \quad 52,318(34 \%) \quad 1240(35 \%)$

$46,191(30 \%)$ up of 8.6 years (maximum follow-up $=10$ years). A higher proportion of women with a stroke had worse socioeconomic status than women without incident stroke during follow-up. The distribution of biologic and behavioral risk factors for stroke were as expected in women with and without incident stroke. More women with an incident stroke reported fair/poor self-rated health $(16 \%)$ than their peers without an incident stroke (9\%). According to the RUCA coding scheme, 93\% $(n=144,937)$ of WHI participants lived in urban, 4\% $(n=5923)$ large rural, and $3 \%$ $(n=4321)$ small/isolated rural areas.

The mean age at stroke diagnosis was slightly lower for women who lived in large rural areas, compared with those who lived in urban and small rural areas (Table 2). There was a higher proportion of hemorrhagic strokes in women who lived in large rural areas $(23 \%)$ than urban $(15 \%)$ or small rural areas (15\%). A higher proportion of women who lived in small rural areas had good poststroke recovery (29\%) compared with women who lived in urban (27\%) and
$1132(32 \%)$

(continued) 
Table 2. Clinical Characteristics of Women with Incident Stroke by Rural-Urban Residence: Women's Health Initiative $(n=3514)$, 1993-2010

\begin{tabular}{|c|c|c|c|c|}
\hline \multirow[b]{2}{*}{ Characteristic } & \multicolumn{4}{|c|}{ Rural-urban category } \\
\hline & $\begin{array}{c}\text { Total } n=3514 \\
N(\%)\end{array}$ & $\begin{array}{c}\text { Urban, } N=3268 \\
N(\%)\end{array}$ & $\begin{array}{c}\text { Large rural, } N=129, \\
N(\%)\end{array}$ & $\begin{array}{c}\text { Small rural, } N=117, \\
N(\%)\end{array}$ \\
\hline \multicolumn{5}{|l|}{ Approximate age at diagnosis } \\
\hline Mean (SD) & $73.3(6.8)$ & $73.3(6.8)$ & $72.2(6.5)$ & $73.6(6.2)$ \\
\hline Min, $\max$ & $50.7,89$ & $50.7,89$ & $56.9,85.7$ & $58.3,85.1$ \\
\hline \multicolumn{5}{|l|}{ Stroke type } \\
\hline Ischemic & $2654(76)$ & $2472(76)$ & $94(73)$ & $88(75)$ \\
\hline Hemorrhagic & $548(16)$ & $501(15)$ & $30(23)$ & $17(15)$ \\
\hline Other/missing & $312(9)$ & $295(9)$ & $5(4)$ & $12(10)$ \\
\hline \multicolumn{5}{|l|}{ Glasgow Stroke Outcome Scale } \\
\hline 1: Good recovery & $961(27)$ & $892(27)$ & $35(27)$ & $34(29)$ \\
\hline 2: Moderately disabled & $896(26)$ & $821(25)$ & $45(35)$ & $30(26)$ \\
\hline 3: Severely disabled & $856(24)$ & $808(25)$ & $20(16)$ & $28(24)$ \\
\hline 4: Vegetative survival & $18(1)$ & $18(1)$ & 0 & 0 \\
\hline 5: Deceased & $323(9)$ & $298(9)$ & $14(11)$ & $11(9)$ \\
\hline 6: Unable to assign category/missing & $460(13)$ & $431(13)$ & $15(12)$ & $14(12)$ \\
\hline \multicolumn{5}{|l|}{ Stroke outcome $(n=3054)$ : } \\
\hline Poor (Glasgow Stroke Outcome Scale $=3,4$ or 5 ) & $1197(39)$ & $1124(40)$ & $34(30)$ & $39(38)$ \\
\hline Good $/$ moderate (Glasgow Stroke Outcome Scale $=1$ or 2 ) & $1857(61)$ & $1713(60)$ & $80(70)$ & $64(62)$ \\
\hline
\end{tabular}

large rural areas (27\%). However, a higher proportion of women who lived in large rural areas died as a result of their stroke (11\%) than women who lived in urban or small rural areas (both $9 \%$ ).

We observed a modest reduction in risk of incident stroke among women who lived in urban (adjusted hazard ratio [aHR]: 0.86 , confidence interval [95\% CI]: 0.71-1.05) and large rural areas (aHR: 0.79, 95\% CI: 0.60-1.04) compared women who lived in small rural areas (Table 3). Nevertheless, a risk difference ranging from a $29 \%$ decreased risk to $5 \%$ increased risk for incident stroke comparing women residing in urban to small rural areas, and between a $40 \%$ decreased risk to a $4 \%$ increased risk comparing women who lived in large to small rural areas, is also compatible with our data, given our assumptions. In contrast, women who lived in urban compared with large rural areas had a similarly modest increased risk of stroke. However, a risk

Table 3. Relationship Between Rural-Urban Residence and Incident Stroke: Women's Health Initiative $(n=155,186), 1993-2010$

\begin{tabular}{lcc}
\hline $\begin{array}{l}\text { Rural-urban } \\
\text { comparisons }\end{array}$ & $\begin{array}{c}\text { Unadjusted, HR } \\
(\mathbf{9 5 \% ~ C l )}\end{array}$ & $\begin{array}{c}\text { Adjusted, HR } \\
\mathbf{( 9 5 \% ~ C l )}\end{array}$ \\
\hline Urban & $0.84(0.70-1.01)$ & $0.86(0.71-1.05)$ \\
Large rural & $0.81(0.63-1.03)$ & $0.79(0.60-1.04)$ \\
Small rural (reference) & 1.00 & 1.00 \\
Urban & $1.05(0.88-1.25)$ & $1.09(0.89-1.32)$ \\
Large rural (reference) & 1.00 & 1.00 \\
\hline
\end{tabular}

Adjustments: race, smoking, income, education, physical activity, living alone, hypertension, treatment for diabetes, and atrial fibrillation; age was used as the time scale.

$\mathrm{Cl}$, confidence interval; $\mathrm{HR}$, hazard ratio. difference ranging from an $11 \%$ decreased to a $32 \%$ increased risk is also compatible with our data, given our assumptions (aHR: 1.09, 95\% CI: 0.89-1.32).

Stroke outcome data were available for 3024 women. In univariable models we observed lower probability of poor stroke outcome (Glasgow score of 3, 4 or 5) among women who lived in urban and large rural compared with small rural areas (Table 4). However, a 26\% lower odds to a $37 \%$ increased probability of poor stroke outcome in urban compared with small rural areas is also compatible with our data, given our assumptions. In contrast, for women who lived in large rural compared with small rural areas, a proportion difference ranging from a $63 \%$ reduction to a small $7 \%$ increased odds is also compatible with our data, given our assumptions. Similarly, our adjusted results for women who lived in large rural compared with small rural areas suggested a 13\% decreased risk;

Table 4. Relationship Between Rural-Urban Residence and Stroke Outcome: Women's Health Initiative $(n=3054), 1993-2010$

\begin{tabular}{lcc}
\hline $\begin{array}{l}\text { Rural-urban } \\
\text { comparisons }\end{array}$ & $\begin{array}{c}\text { Unadjusted, OR } \\
(95 \% \mathrm{Cl})\end{array}$ & $\begin{array}{c}\text { Adjusted, OR } \\
\mathbf{9 5 \%} \mathrm{Cl})\end{array}$ \\
\hline Urban & $1.02(0.74-1.37)$ & $1.10(0.78-1.55)$ \\
Large rural & $0.71(0.47-1.07)$ & $0.87(0.55-1.36)$ \\
Small rural (reference) & 1.00 & 1.00 \\
Urban & $1.41(1.06-1.88)$ & $1.27(0.93-1.74)$ \\
Large rural (reference) & 1.00 & 1.00 \\
\hline
\end{tabular}

Adjustments: age, race, smoking, income, education, physical activity, living alone, hypertension, treatment for diabetes, atrial fibrillation, and trial membership.

$\mathrm{OR}$, odds ratio. 
however, a risk difference ranging from a $45 \%$ reduction in risk to a $36 \%$ increased risk is also compatible with our data. Similarly, our adjusted point estimates for women who lived in urban compared with small rural areas had $10 \%$ increased risk of poor stroke outcome; however, a risk difference from a $22 \%$ decreased risk to a sizeable $55 \%$ increased risk is also compatible with the data, given our assumptions. Finally, in univariable models, those who lived in urban compared with large rural areas, were more likely to have poor stroke outcome (odds ratio [OR]: 1.41, 95\% CI: 1.061.88 ), but the association was slightly attenuated after adjustment for covariates (adjusted OR [aOR]: 1.27, 0.93-1.74). However, a difference in odds for women who lived in urban compared with large rural areas ranging from a $7 \%$ reduction to a sizeable $74 \%$ increase in odds of poor stroke outcome, after adjusting for covariates, is also compatible with our data, given our assumptions.

\section{Discussion}

The National Institutes of Health includes rural residents in their definition of health disparity populations, ${ }^{37}$ because disease prevalence and mortality rates are higher in these areas than in the overall U.S. population. ${ }^{38}$ Our adjusted point estimates suggests a possible risk difference ranging from a sizeable $29 \%$ reduced risk to a relatively small $5 \%$ increased risk of stroke in postmenopausal women who lived in urban compared with small rural areas,. For women who lived in large rural compared with small rural areas, our results suggest a possible risk difference ranging from a $40 \%$ decreased risk to a small $4 \%$ increased risk. We found evidence of a difference in odds ranging from a $10 \%$ reduced probability to a $108 \%$ increase in odds of poor stroke outcome among women who lived in urban compared with large rural areas.

Our results are similar to those reported in another study examining rural-urban residence and stroke risk, which used data from 18,705 men and women enrolled in the REGARDS study. Specifically, they found that compared with urban residents, those who lived in large rural had $28 \%$ increased risk of stroke, but risk differences ranging from a $4 \%$ reduction in risk to a sizeable $44 \%$ increased risk was also compatible with their data. In comparing stroke risk among those who lived in small rural areas to urban, they reported the former had a 19\% higher risk, although the range of $6 \%$ decreased risk to $50 \%$ increased risk is also compatible with their data. They also reported point esti- mates suggesting higher case fatality for individuals living in large rural compared with urban areas (OR: 1.13, 95\% CI: 0.63-2.01) and point estimates suggesting a protective effect for small rural area residents (OR: $0.70,95 \%$ CI: 0.33-1.44); however, the uncertainty around all of their estimates was non-negligible. We add to this literature evidence from a large longitudinal cohort study of postmenopausal women, which suggests that women who live in small rural compared with large rural and urban areas, and women who live in urban compared with large rural areas may have higher stroke risk and worse stroke severity. Future research is needed to confirm our findings and examine potential mediating pathways.

Intrarural disparities in mortality exist, with rural areas of modest population size and spatially close to urban areas, having greater mortality burden than the most rural areas. ${ }^{39}$ In our study, a higher proportion of women who resided in large rural areas had a hemorrhagic stroke (23\%) compared with women who lived in urban and small rural areas (both 15\%). The prevalence of hemorrhagic strokes range from $6.5 \%$ to $16.6 \%{ }^{40}$ Future studies should explore intrarural differences in stroke type. Potential reasons for our modest results regarding a rural penalty for stroke risk and poor stroke outcome could be insufficient variability in rural-urban residence, and/or that rural residents commonly receive their stroke care in urban settings, ${ }^{41}$ or have telestroke care in rural care settings, ${ }^{42,43}$ which could reduce the difference in quality of care by rural-urban residence.

Our findings may also be the result of successful stroke care quality improvement programs, such as the Paul Coverdell National Acute Stroke Program, the American Heart Association and the American Stroke Association, and the Joint Commission's Primary Stroke Center Certification program, initiatives that sought to organize and coordinate acute stroke care in rural hospitals. ${ }^{44}$ Furthermore, evidence suggests that rural populations are more likely to have a usual source of health care than their urban counterparts. ${ }^{44}$ It is unclear why women who lived in urban compared with large rural areas may have higher stroke risk and worse poststroke outcomes.

Future research with larger study populations should be able to confirm this association and identify intervening pathways. In interpreting our results, the following limitations should be considered. First, the WHI is not a population-based sample, and study participants had higher socioeconomic position and were 
healthier than the general U.S. population. However, the racial/ethnic composition of the WHI is comparable with the U.S. population. In our analysis subsample, $9 \%$ of the participants had missing stroke type and stroke outcome data. The heterogeneity of our sample in terms of rurality of residence was low, as was the risk of stroke in our cohort, both of which may have decreased our power to detect rural-urban differences in stroke risk and outcomes. Given the hypothesis generating nature of this research, we did not adjust for multiple comparisons.

Our study has several strengths that extend the current literature. First, to our knowledge, ours is the largest study of the influence of rural-urban residence on stroke risk and outcome in postmenopausal women. ${ }^{45}$ We were also able to control the analysis for lifestyle factors not available in many stroke databases. Another strength of our work is the geographic heterogeneity of the WHI, and that we had 3514 stroke events, which allowed us to estimate the impact of rural-urban residence on stroke risk among postmenopausal women. WHI is a rich large data set to study stroke in aging women, given the long-term followup and large study population. ${ }^{46}$

\section{Summary}

Our results suggest that postmenopausal women who live in small rural compared with large rural and urban areas may have higher stroke risk and worse stroke severity, and that women who live in urban compared with large rural areas may have higher stroke risk and worse stroke outcomes. Since most people will survive their stroke, poststroke disability is the ultimate challenge stroke patients and their families face, as two thirds of stroke patients have a severe/moderate or mild disability. ${ }^{47,48}$ To address the projected human, economic, and societal burden of stroke, it is imperative that future research identify novel risk factors for stroke risk and poor stroke outcome among higher risk groups, including geographic areas most affected.

\section{Author Disclosure Statement}

No competing financial interests exist.

\section{Funding Information}

The WHI program is funded by the National Heart, Lung, and Blood Institute, National Institutes of Health, U.S. Department of Health and Human Services through contracts HHSN268201600018 C, HHSN268201600001
C, HHSN268201600002 C, HHSN268201600003 C, and HHSN268201600004 C.

\section{References}

1. Mozaffarian D, Benjamin EJ, Go AS, et al. Heart disease and stroke statistics-2016 update a report from the American Heart Association. Circulation 2016;133:e38-e48.

2. Roger VL, Go AS, Lloyd-Jones DM, et al. Heart disease and stroke statistics-2011 update: A report from the American Heart Association. Circulation 2011;123:e18-e209.

3. Mozaffarian D, Benjamin EJ, Go AS, et al. Executive summary: Heart disease and stroke statistics - 2015 update: A report from the American Heart Association. Circulation 2015;131:434-441.

4. Ovbiagele B, Goldstein LB, Higashida RT, et al. Forecasting the future of stroke in the United States: A policy statement from the American Heart Association and American Stroke Association. Stroke 2013;44:2361-2375.

5. Roger VL, Go AS, Lloyd-Jones DM, et al. Executive summary: Heart disease and stroke statistics-2012 update: A report from the American Heart Association. Circulation 2012;125:188-197.

6. Lisabeth L, Bushnell C. Stroke risk in women: The role of menopause and hormone therapy. Lancet Neurol 2012;11:82-91.

7. Whitson $H E$, Landerman LR, Newman AB, Fried LP, Pieper CF, Cohen HJ. Chronic medical conditions and the sex-based disparity in disability: The Cardiovascular Health Study. J Gerontol A Biol Sci Med Sci 2010;65: 1325-1331.

8. Caldwell JT, Ford CL, Wallace SP, Wang MC, Takahashi LM. Intersection of living in a rural versus urban area and race/ethnicity in explaining access to health care in the United States. Am J Public Health 2016;106: 1463-1469.

9. Arcury TA, Preisser JS, Gesler WM, Powers JM. Access to transportation and health care utilization in a rural region. J Rural Health 2005;21: 31-38.

10. Howard G, Evans GW, Pearce K, et al. Is the stroke belt disappearing? An analysis of racial, temporal, and age effects. Stroke 1995;26:1153-1158.

11. Howard G, Kleindorfer DO, Cushman M, et al. Contributors to the excess stroke mortality in rural areas in the United States. Stroke 2017;48: 1773-1778.

12. Howard VJ, Kleindorfer DO, Judd SE, et al. Disparities in stroke incidence contributing to disparities in stroke mortality. Ann Neurol 2011;69: 619-627.

13. Gonzales S, Mullen MT, Skolarus L, Thibault DP, Udoeyo U, Willis AW. Progressive rural-urban disparity in acute stroke care. Neurology 2017;88: 441-448.

14. Ricketts TC, Johnson-Webb KD, Randolph, RK. Populations and places in rural America. New York: Oxford University Press, 1999.

15. DeVoe JE, Fryer GE, Phillips R, Green L. Receipt of preventive care among adults: insurance status and usual source of care. Am J Public Health 2003;93:786-791.

16. Larson SL, Fleishman JA. Rural-urban differences in usual source of care and ambulatory service use: Analyses of national data using Urban Influence Codes. Med Care 2003;41(7 Suppl):III65-III74.

17. Schur CL, Franco SJ. Access to health care. New York: Oxford University Press, 1999.

18. Larson S, Correa-de-Araujo R. Preventive health examinations: A comparison along the rural-urban continuum. Women's Health Issues 2006;16:80-88.

19. Cushman M, Cantrell RA, McClure LA, et al. Estimated 10-year stroke risk by region and race in the United States. Ann Neurol 2008;64:507-513.

20. Howard G, Prineas R, Moy C, et al. Racial and geographic differences in awareness, treatment, and control of hypertension: The REasons for Geographic snd Racial Differences in Stroke study. Stroke 2006;37: 1171-1178.

21. Howard G. Ancel keys lecture: Adventures (and misadventures) in understanding (and reducing) disparities in stroke mortality. Stroke 2013; 44:3254-3259.

22. Sergeev AV. Racial and rural-urban disparities in stroke mortality outside the Stroke Belt. Ethn Dis 2011;21:307-313.

23. Gillum RF, Ingram DD. Relation between residence in the southeast region of the United States and stroke incidence. The NHANES I Epidemiologic Followup Study. Am J Epidemiol 1996;144:665-673. 
24. Bellamy GR, Bolin JN, Gamm LD. Rural Healthy People 2010, 2020, and beyond: The need goes on. Fam Commun Health 2011;34:182-188.

25. Burgin W, Staub L, Chan W, et al. Acute stroke care in non-urban emergency departments. Neurology 2001;57:2006-2012.

26. Phipps MS, Jia H, Chumbler NR, et al. Rural-urban differences in inpatient quality of care in US veterans with ischemic stroke. J Rural Health 2014;30: $1-6$.

27. Hays J, Hunt JR, Hubbell FA, et al. The Women's Health Initiative recruitment methods and results. Ann Epidemiol 2003;13(9 Suppl): S18-S77.

28. Design of the Women's Health Initiative clinical trial and observational study. The Women's Health Initiative Study Group. Control Clin Trials 1998;19:61-109.

29. Matthews KA, Shumaker SA, Bowen DJ, et al. Women's health initiative. Why now? What is it? What's new? Am Psychol 1997:52:101-116.

30. Cromartie J. Rural-Urban Commuting Area Codes: Overview and Documentation. 2012. Available at: www.ers.usda.gov/data-products/ rural-urban-commuting-area-codes.aspx Accessed September 13, 2017.

31. Whitsel EA, Quibrera PM, Smith RL, et al. Accuracy of commercial geocoding: Assessment and implications. Epidemiol Perspect Innov 2006; 3:8.

32. Whitsel EA, Rose KM, Wood JL, Henley AC, Liao D, Heiss G. Accuracy and repeatability of commercial geocoding. Am J Epidemiol 2004;160:10231029.

33. Sealy-Jefferson S, Roseland ME, Cote ML, et al. Rural-urban residence and stage at breast cancer diagnosis among postmenopausal women: The Women's Health Initiative. J Womens Health (Larchmt) 2019;28:276-283.

34. Hall SA, Kaufman JS, Ricketts TC. Defining urban and rural areas in U.S. epidemiologic studies. J Urban Health 2006;83:162-175.

35. Wassertheil-Smoller S, Hendrix S, Limacher M, et al. Effect of estrogen plus progestin on stroke in postmenopausal women: The Women's Health Initiative: A randomized trial. JAMA 2003;289:2673-2684.

36. Amrhein V, Greenland S, McShane B. Scientists rise up against statistical significance. Nature 2019;567:305-307.

37. National Institutes of Health. NLM Health Disparities Strategic Plan and Budget: Fiscal Years 2009-2013. Bethesda, MD: National Library of Medicine, 2013.

38. Meit M, Knudson A, Gilbert T, et al. The 2014 update of the rural-urban chartbook. Bethesda, MD: Rural Health Reform Policy Research Center, 2014.

39. James W, Cossman JS. Long-term trends in Black and White mortality in the rural United States: Evidence of a race-specific rural mortality penalty. J Rural Health 2017;33:21-31.

40. Feigin VL, Lawes CM, Bennett DA, Anderson CS. Stroke epidemiology: A review of population-based studies of incidence, prevalence, and casefatality in the late 20th century. Lancet Neurol 2003;2:43-53.
41. Rodriguez D, Cox M, Zimmer LO, et al. Similar secondary stroke prevention and medication persistence rates among rural and urban patients. J Rural Health 2011;27:401-408.

42. Kulcsar M, Gilchrist S, George MG. Improving stroke outcomes in rural areas through telestroke programs: An examination of barriers, facilitators, and state policies. Telemed J E Health 2014;20:3-10.

43. Schwamm L. American Heart Association Stroke Council; Council on Epidemiology and Prevention; Interdisciplinary Council on Peripheral Vascular Disease; Council on Cardiovascular Radiology and Intervention Recommendations for the implementation of telemedicine within stroke systems of care: A policy statement from the American heart association. Stroke 2009;40:2635-2660.

44. Gorelick PB. Primary and comprehensive stroke centers: History, value and certification criteria. J Stroke 2013;15:78.

45. Bell CL, LaCroix A, Masaki K, et al. Prestroke factors associated with poststroke mortality and recovery in older women in the W omen's Health I nitiative. J Am Geriatr Soc 2013;61:1324-1330.

46. Wassertheil-Smoller S, Kaplan RC, Salazar CR. Stroke findings in the Women's Health Initiative. Paper presented at: Semin Reprod Med 2014 32:438-446.

47. Kelly-Hayes M, Beiser A, Kase CS, Scaramucci A, D'Agostino RB, Wolf PA. The influence of gender and age on disability following ischemic stroke: The Framingham study. J Stroke Cerebrovasc Dis 2003;12:119-126.

48. Wilkinson PR, Wolfe CD, Warburton FG, et al. A long-term follow-up of stroke patients. Stroke 1997;28:507-512.

Cite this article as: Sealy-Jefferson $S$, Roseland $M$, Cote $M L$, Lehman A, Whitsel EA, Booza J, Simon MS (2020) Rural-urban residence and stroke risk and severity in postmenopausal women: The Women's Health Initiative, Women's Health Report 1:1, 326-333, DOI: 10.1089/ whr.2020.0034

$\begin{aligned} & \text { Abbreviations Used: } \\ & \mathrm{aHR}=\text { adjusted hazard ratio } \\ & \mathrm{aOR}=\text { adjusted odds ratio } \\ & \mathrm{Cl}=\text { confidence interval } \\ & \mathrm{OR}=\text { odds ratio } \\ & \mathrm{RUCA}=\text { rural-urban commuting area } \\ & \mathrm{WHI}=\text { Women's Health Initiative }\end{aligned}$

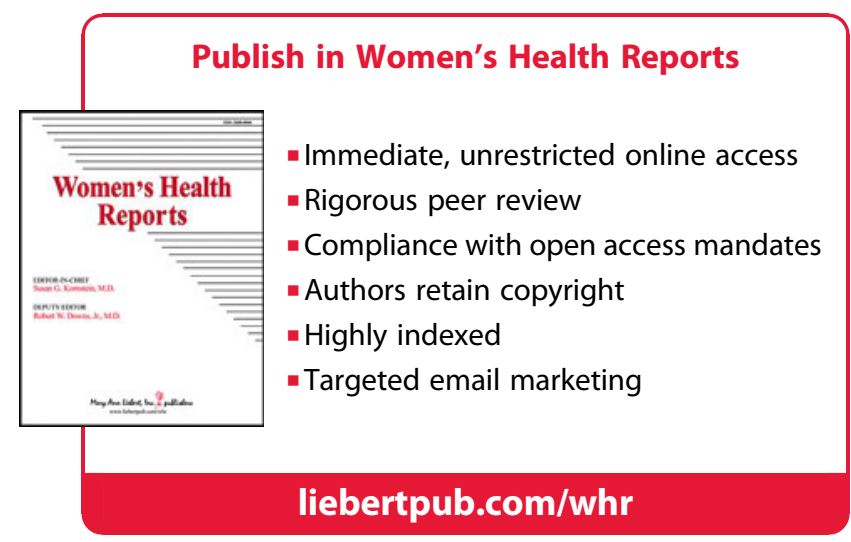

